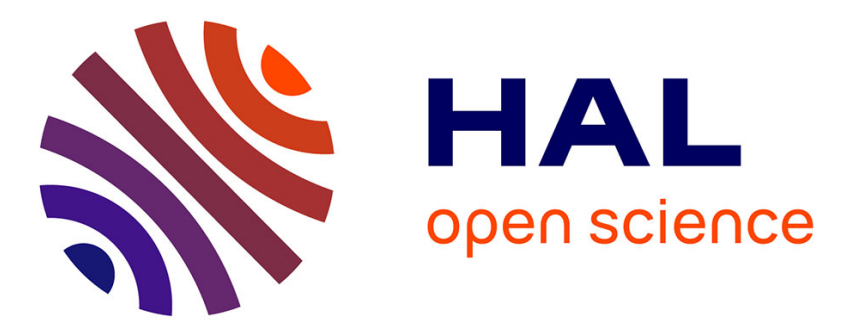

\title{
Porous Boron Carbon Nitride Nanosheets as Efficient Metal-Free Catalysts for the Oxygen Reduction Reaction in Both Alkaline and Acidic Solutions
}

Jiemin Wang, Jian Hao, Dan Liu, Si Qin, David Portehault, Yinwei Li, Ying Chen, Weiwei Lei

\section{To cite this version:}

Jiemin Wang, Jian Hao, Dan Liu, Si Qin, David Portehault, et al.. Porous Boron Carbon Nitride Nanosheets as Efficient Metal-Free Catalysts for the Oxygen Reduction Reaction in Both Alkaline and Acidic Solutions. ACS Energy Letters, 2017, 2 (2), pp.306-312. 10.1021/acsenergylett.6b00602 . hal-01520227

\section{HAL Id: hal-01520227 \\ https: / hal.sorbonne-universite.fr/hal-01520227}

Submitted on 10 May 2017

HAL is a multi-disciplinary open access archive for the deposit and dissemination of scientific research documents, whether they are published or not. The documents may come from teaching and research institutions in France or abroad, or from public or private research centers.
L'archive ouverte pluridisciplinaire HAL, est destinée au dépôt et à la diffusion de documents scientifiques de niveau recherche, publiés ou non, émanant des établissements d'enseignement et de recherche français ou étrangers, des laboratoires publics ou privés. 


\section{Letter}

Porous Boron Carbon Nitride Nanosheets as Efficient Metal-free Catalysts for the Oxygen Reduction Reaction in Both Alkaline and Acidic Solutions

Jiemin Wang, Jian Hao, Dan Liu, Si Qin, David Portehault, Yinwei Li, Ying Chen, and Weiwei Lei

ACS Energy Lett., Just Accepted Manuscript • DOI: 10.1021/acsenergylett.6b00602 • Publication Date (Web): 03 Jan 2017

Downloaded from http://pubs.acs.org on January 5, 2017

\section{Just Accepted}

"Just Accepted" manuscripts have been peer-reviewed and accepted for publication. They are posted online prior to technical editing, formatting for publication and author proofing. The American Chemical Society provides "Just Accepted" as a free service to the research community to expedite the dissemination of scientific material as soon as possible after acceptance. "Just Accepted" manuscripts appear in full in PDF format accompanied by an HTML abstract. "Just Accepted" manuscripts have been fully peer reviewed, but should not be considered the official version of record. They are accessible to all readers and citable by the Digital Object Identifier (DOI®). "Just Accepted" is an optional service offered to authors. Therefore, the "Just Accepted" Web site may not include all articles that will be published in the journal. After a manuscript is technically edited and formatted, it will be removed from the "Just Accepted" Web site and published as an ASAP article. Note that technical editing may introduce minor changes to the manuscript text and/or graphics which could affect content, and all legal disclaimers and ethical guidelines that apply to the journal pertain. ACS cannot be held responsible for errors or consequences arising from the use of information contained in these "Just Accepted" manuscripts. 


\title{
Porous Boron Carbon Nitride Nanosheets as
}

\author{
Efficient Metal-free Catalysts for the Oxygen
}

\section{Reduction Reaction in Both Alkaline and Acidic}

\section{Solutions}

\author{
Jiemin Wang, ${ }^{\dagger}$ Jian Hao, ${ }^{\dagger,+}$ Dan Liu, ${ }^{* \dagger}$ Si Qin, ${ }^{\dagger}$ David Portehault, ${ }^{\S}$ Yinwei Li, ${ }^{*}$ Ying Chen ${ }^{\dagger}$ and \\ Weiwei Lei ${ }^{* \dagger}$ \\ ${ }^{\dagger}$ Institute for Frontier Materials, Deakin University, 75 Pigdons Road, Waurn Ponds, 3216,VIC, \\ Australia
}

Emails: weiwei.lei@deakin.edu.au;dan.liu@deakin.edu.au

${ }^{\ddagger}$ School of Physics and Electronic Engineering, Jiangsu Normal University, Xuzhou,Jiangsu, 221116, China

${ }^{\S}$ Sorbonne Universités, UPMC Université Paris 06, CNRS, Collège de France, Laboratoire de Chimie de la Matière Condensée de Paris (LCMCP), 11 place Marcelin Berthelot, F-75005 Paris, France 
ABSTRACT: The carbon materials have become a hot topic as potential substitution of $\mathrm{Pt} / \mathrm{C}$ catalysts for oxygen reduction reaction (ORR). However, most of them only prove their catalytic activities in alkaline solutions, which severely limit the applications in polyelectrolyte membrane fuel cells (PEMFCs). To address this issue, here porous boron carbon nitride (BCN) nanosheets are fabricated by a facile and efficient polymer sol-gel method, which involves the annealing of polyvinylic akohol (PVA), boric acid, guanidine and poly (ethylene oxide-co- propylene oxide) (P123) gel mixtures. The as-prepared porous BCN nanosheets possess a high surface area of 817 $\mathrm{m}^{2} / \mathrm{g}$ and display impressive ORR catalytic performance in both alkaline and acid media, rivalling that of commercial $\mathrm{Pt} / \mathrm{C}$ and other latest reported carbon materials. Importantly, the resulting metal-free catalysts exhibit much greater durability and higher methanol tolerance in both alkaline and acid environment as well. This study provides a new sight for metal-free ORR catalysts which are practicable in industrial fuel cells.

\section{TOC GRAPHICS}

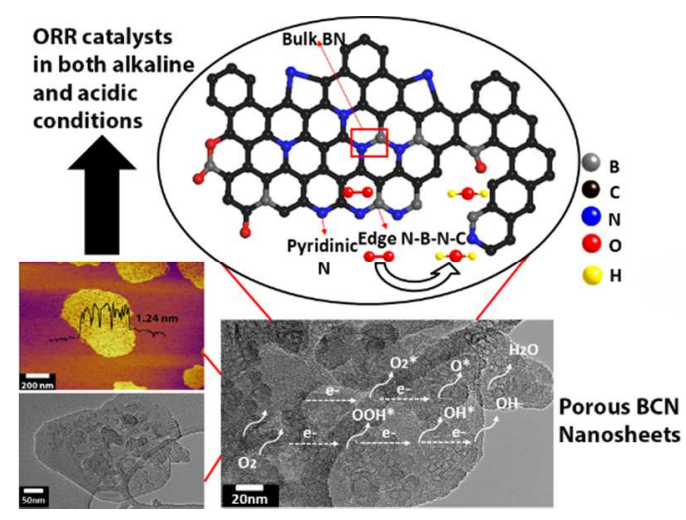


The ORR is pivotal in fuel cells and metal batteries. ${ }^{1}$ In general, the noble metal Pt-based catalysts dominate in the ORR field owing to excellent electrocatalytic activity. ${ }^{2}$ Nevertheless, the scarcity, easy deactivation by CO poisoning, fuel crossover effect, and low durability greatly impede the development of Pt based catalysts. ${ }^{3-5}$ To address these issues, other materials such as transition-metal dichalcogenides ${ }^{6}$ and carbon nanomaterials ${ }^{7,8}$ are favoured as promising candidates. Among them, metal-free heteroatom-doped (such as B,N,S,P) carbon nanomaterials are predominate with superior ORR catalytic performance by providing not only large surface area but also more polarized active sites for oxygen adsorption or splitting. ${ }^{9-11}$ However, most of them are mainly focused on behaviours in alkaline conditions. Only a few metal-free carbon nanomaterials catalysts can be affordable in the acidic media, ${ }^{12-15}$ due to the poor durability and electroactivity deterioration. However, currently, most fuel cells are equipped with acid electrolyte. ${ }^{4,12}$ Meanwhile, those carbon nanomaterials with benign behaviours in acid conditions are commonly functionalized with metal impurities or complexes, ${ }^{16,17}$ which unavoidably increase the cost. Therefore, to cater for the current commercial market, the development of a practical metal-free heteroatom-doped carbon nanomaterial applicable in both alkaline and acid environments is a big challenge.

Previous research has witnessed the boost of graphene as prominent two-dimensional (2D) nanomaterial in the energy applications including energy storage and electrocatalysis, $5,18,19$ related to its pronounced physiochemical and electronic properties with elegant planar geometry. Structurally analogous to graphene, 2D hexagonal boron nitride (h-BN) is of extensive interests as well. In spite of being a wide gap semiconductor, h-BN displays excellent thermal conductivity, chemical stability and mechanical properties in the applications of polymer composites, ${ }^{20}$ hydrogen storage ${ }^{21}$ and water cleaning. ${ }^{22-25}$ Related to but different from either 
graphene or h-BN, ternary boron carbon nitride $(\mathrm{BCN})$ nanosheets are likely to possess striking performances by integrating the merits of both graphene and h-BN. Furthermore, it has been reported that the band gap $(0-5.5 \mathrm{eV})$ of $\mathrm{BCN}$ is tuneable via adjusting the content of each heteroelement. $^{26-28}$ In addition, heteropolar B, N bonding largely stimulates electroactivity, thus benefiting the versatility of BCN nanosheets in electro energy applications. ${ }^{29-31}$ Up to now, BCN nanosheets have placed values on lithium-ion batteries, ${ }^{32}$ oxygen reduction reaction (ORR), ${ }^{33}$ hydrogen evolutions (HER) $)^{34}$ and supercapacitors, ${ }^{35}$ which rival those of other $2 \mathrm{D}$ nanomaterials. Although B, N doped CNTs, ${ }^{36,37}$ graphene ${ }^{38-40}$ or BCN nanostructures ${ }^{41-45}$ have been reported as effective ORR catalysts in alkaline media, no research has proposed the ORR electrocatalysis by metal-free $\mathrm{BCN}$ in acid condition. Hence, it is a challenge to developing a BCN-based nanostructured electrocatalyst performing not only in alkaline, but also in acid environment.

Herein, we design a simple and efficient polymer sol-gel method to prepare porous BCN nanosheets. In contrast with other traditional methods such as chemical vapor deposition (CVD), and microwave plasma $\mathrm{CVD},{ }^{46,47}$ this route is of large scale production, low cost, and does not require high energy, vacuum systems and catalysts. The as-obtained BCN nanosheets reveal a high surface area of $817 \mathrm{~m}^{2} / \mathrm{g}$ with both meso and micro pores. Our BCN catalysts demonstrate impressive ORR catalytic performances in both alkaline and acid conditions, comparable to $\mathrm{Pt} / \mathrm{C}$ and other carbon nanomaterials ever reported. In addition, the products also manifest great longterm stability and better tolerance to the methanol crossover effect in both alkaline and acid media than commercial $\mathrm{Pt} / \mathrm{C}$. Obviously, the $\mathrm{BCN}$ nanosheets with porous nanostructure pave a potential way for substitution of $\mathrm{Pt} / \mathrm{C}$ as effective metal-free ORR catalysts in industrial fuel cells. 


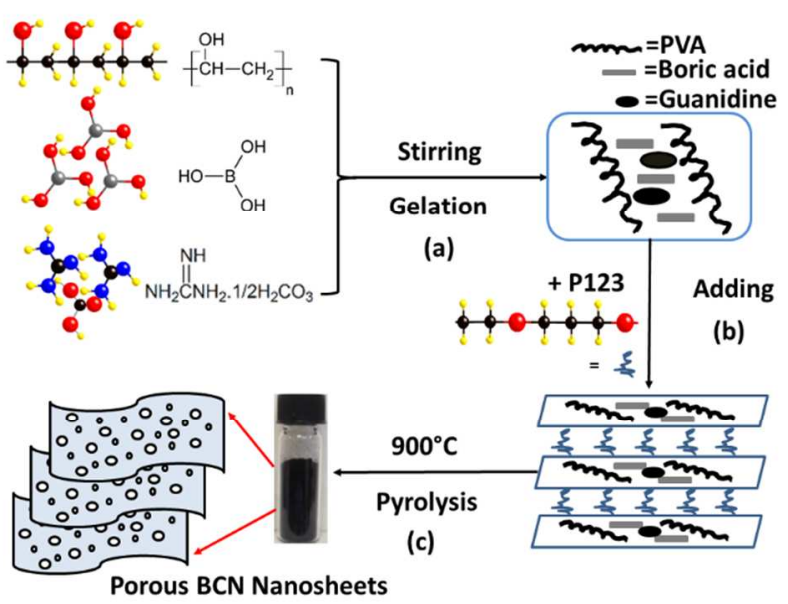

Scheme 1. Schematic synthesis process of porous BCN nanosheets including: (a) The gelation of polymer precursor. (b) The adding of $\mathrm{P} 123$ and (c) The pyrolysis at $900^{\circ} \mathrm{C}$ under $\mathrm{N}_{2}$.

The synthetic strategy is schematically illustrated in Scheme 1. Firstly, the polymeric gel precursor is formed by hydroxyl and amino group crosslinking between polyvinylic akohol (PVA), boric acid and guanidine carbonate salt. Then the polymeric precursor is further cured by introduction of P123 for both porosity development ${ }^{48,49}$ and nanosheets morphology control under the carbonation process. ${ }^{50}$ After annealing at $900^{\circ} \mathrm{C}$ in $\mathrm{N}_{2}$, the precursor gel architecture is gradually converted into a 2D porous layered structure and $\mathrm{B}, \mathrm{N}, \mathrm{C}$ atoms are mutually bonded upon carbonization. Finally the porous BCN nanosheets are generated in a mass scale. 

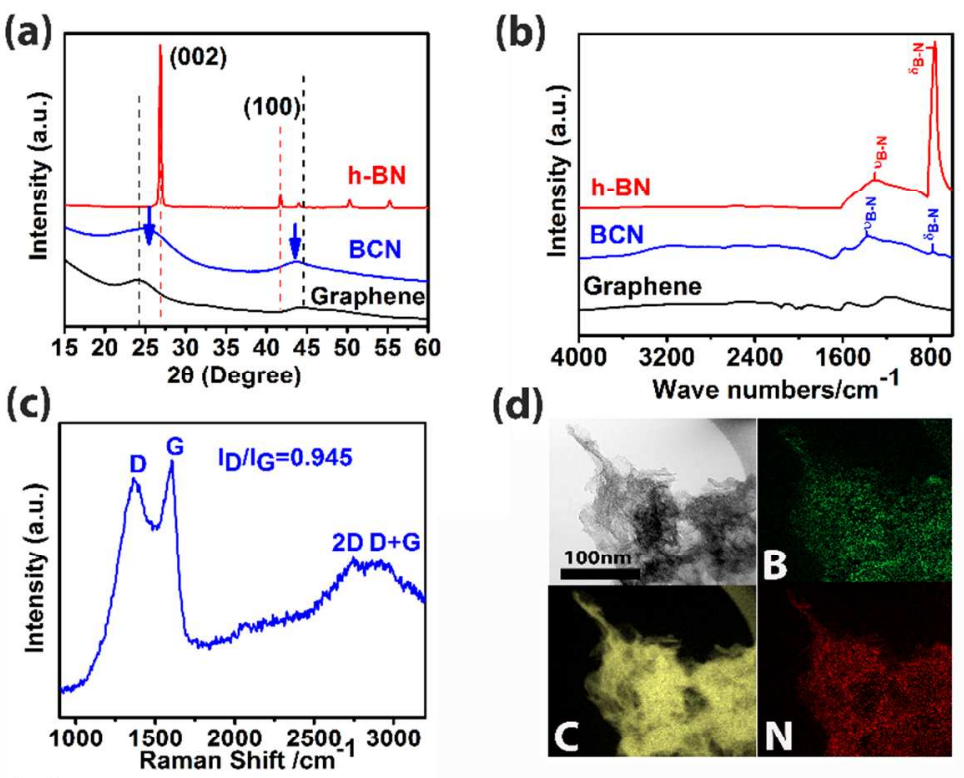

(d)
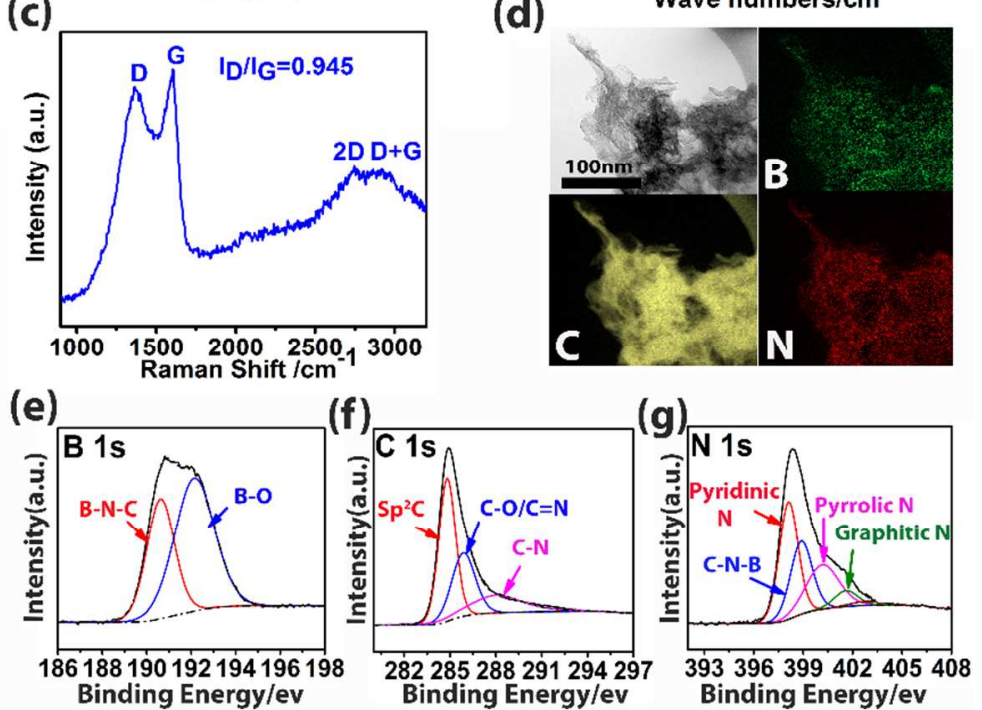

Figure 1. Characterization of the porous BCN nanosheets. a) XRD, b) FTIR and c) Raman of BCN nanosheets. d) TEM image of BCN nanosheets and corresponding EDS mapping of B,C,N elements, e) XPS B 1s spectrum, f) XPS C1s spectrum and g) XPS of $\mathrm{N} 1 \mathrm{~s}$ spectrum of BCN nanosheets.

The X-Ray Diffraction (XRD) pattern (Figure 1a) suggests two characteristic peaks at around $26^{\circ}$ and $43^{\circ}$ respectively, typically representing (002) and (101) interlayers reflections of BCN. ${ }^{26}$ Compared with reference h-BN and graphene, these intervenient shifting broad humps of (002) and (101) imply the presence of $\operatorname{defects}^{28}$ and existence of $\mathrm{sp}^{2}$-bonded conjugated graphitic carbons containing structural heteroatoms integrated within small stacks. ${ }^{51}$ In the Fourier Transform Infrared (FTIR) spectrum (Figure 1b), two small bands at around $1380 \mathrm{~cm}^{-1}$ and $900 \mathrm{~cm}^{-1}$ could be attributed to B-N stretching bands $\left(v_{\mathrm{B}-\mathrm{N}}\right)$ and B-N bending bands $\left(\delta_{\mathrm{B}-\mathrm{N}}\right)$ respectively.

Evidently, these two bands show a little blue shift in contrast with that of h-BN, highlighting the conjugative effect of C-N-B in the ternary system. ${ }^{38,39}$ The Raman spectrum (Figure 1c) 
shows the characteristic signals of the D and $\mathrm{G}$ bands at around $1360 \mathrm{~cm}^{-1}$ and $1600 \mathrm{~cm}^{-1}$ as well as two weak $2 \mathrm{D}$ and $\mathrm{D}+\mathrm{G}$ bands at 2668 and $2900 \mathrm{~cm}^{-1}$, consistent with previously reported BCN nanosheets. ${ }^{47}$ A typical shift of the $\mathrm{G}$ band $\left(1600 \mathrm{~cm}^{-1}\right)$ in $\mathrm{BCN}$ is observed from pure graphene $\left(1580 \mathrm{~cm}^{-1}\right)$, attributing to the structural distortion of graphitic carbon with different bond lengths of N-B and C-N. ${ }^{41}$ Besides, the appearance of relatively weak $2 \mathrm{D}$ band indicates the presence of a few layers in BCN nanosheets, ${ }^{46}$ conforming to XRD analysis. Noticeably, the relative intensity of $\mathrm{I}_{\mathrm{D}} / \mathrm{I}_{\mathrm{G}}$, which represents the level of defects and heteroatom doping, ${ }^{52}$ is 0.945 in this study, less than most of the $\mathrm{B}, \mathrm{N}$ co-doped graphene $\left(\mathrm{I}_{\mathrm{D}} / \mathrm{I}_{\mathrm{G}}>1\right)^{38-45}$. On one hand, it suggests that local structures of our BCN nanosheets evolve towards graphitization instead of highly defective and disordered heterojunctions. ${ }^{45,51}$ On the other hand, the balance of electroactive defects and conductive ordered domains might be optimized in our sample, facilitating the electrochemical activities to the most extent. ${ }^{4,49}$ Energy-dispersive spectroscopy (EDS) mapping (Figure 1d) and X-ray photoelectron spectroscopy (XPS) (Figure 1e-g and Figure S1) further demonstrate the existence of B, C and N elements in our sample. From EDS images, it is clear that all the elements $(\mathrm{B}, \mathrm{C}$ and $\mathrm{N})$ are distributed in the nanosheets evenly. The atomic concentration ratio of $\mathrm{BCN}$ is calculated to be $\mathrm{B}_{1} \mathrm{C}_{6.66} \mathrm{~N}_{1.09}$ (B: 11.48 at.\%, $\mathrm{C}: 76.02$ at.\%, N: 12.50 at.\%) from XPS results. The B1s spectra (Figure 1e) could be deconvoluted into two different signals at around $190.6 \mathrm{eV}$ and $192.1 \mathrm{eV}$, indicating the coexistence of B-N-C and B-O bonds accordingly. ${ }^{35,44,53,54}$ The $\mathrm{C} 1 \mathrm{~s}$ spectrum in Figure $1 \mathrm{f}$ highlights that $\mathrm{sp}^{2} \mathrm{C}=\mathrm{C}$ bonding (at $\sim 284.7 \mathrm{eV}$ ) dominates in the whole $\mathrm{BCN}$ conjugated frame. Other two smaller $\mathrm{C} 1 \mathrm{~s}$ peaks at about $286 \mathrm{eV}$ and $289 \mathrm{eV}$ are corresponding to $\mathrm{C}-\mathrm{O} / \mathrm{C}-\mathrm{N}$ and $\mathrm{C}=\mathrm{N}$ bonds respectively. ${ }^{26,35,38}$ Moreover, the deconvolution of high-resolution N1s band describes four types of $\mathrm{N}$ species including pyridinic $\mathrm{N}(\sim 398.2 \mathrm{eV})$, pyrrolic $\mathrm{N}(\sim 400.4 \mathrm{eV})$, quaternary $\mathrm{N}(\sim 401.4 \mathrm{eV})$ and C-N- 
$\mathrm{B}(\sim 399 \mathrm{eV})$ separately (Figure $1 \mathrm{~g}) .^{35,55}$ Interestingly, pyridinic $\mathrm{N}$ accounts for the highest percentage (38.64 at.\%) in the $\mathrm{N}$ atomic concentration, followed by $\mathrm{C}-\mathrm{N}-\mathrm{B}$ bonding (27.6 at.\%), implying that a large number of ORR active sites exists in our BCN nanosheets. ${ }^{43,56,57}$ In agreement with XRD, Raman and FTIR, the XPS results demonstrate the successful synthesis of BCN nanosheets. In addition, the potential complementary effects of $\mathrm{B}$ and $\mathrm{N}$ atoms as well as adjustable electronic structure of carbon should greatly benefit the electrochemical activity as ORR catalysts. ${ }^{27}$
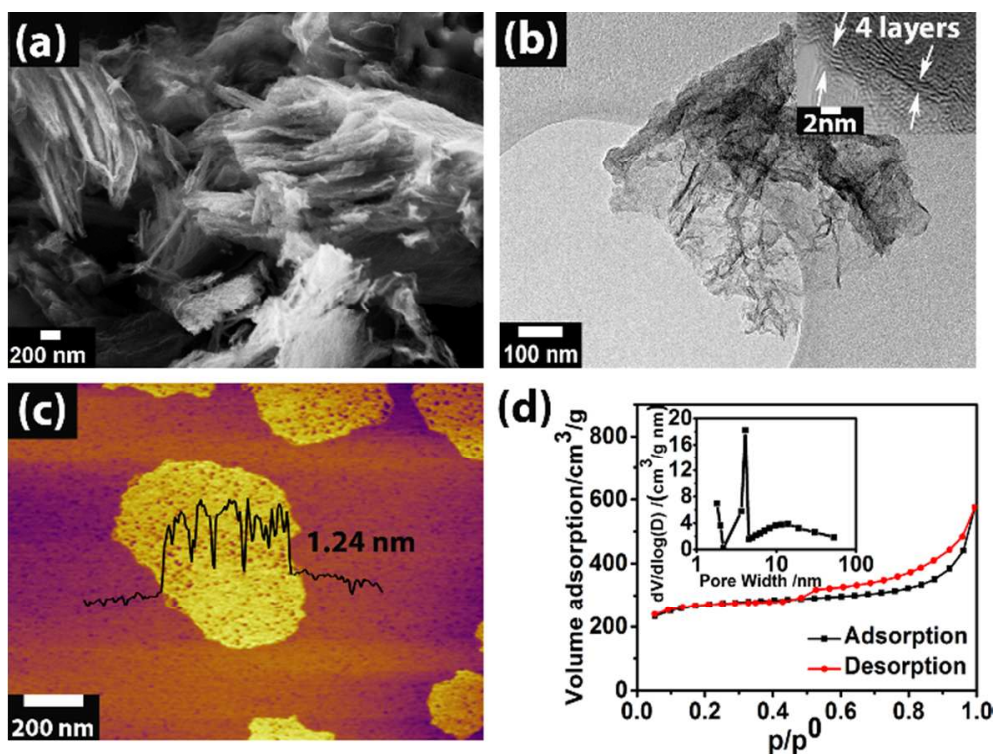

Figure 2. Morphologies of the porous BCN nanosheets. a) SEM, b) TEM and c) AFM pictures of BCN nanosheets. Inset of (b) shows the edge folding of the BCN sheet with 3-5 layers. d) Nitrogen adsorption/desorption isotherms of BCN nanosheets, the inset shows the corresponding pore size distributions.

Scanning electron microscope (SEM) displays the fluffy, thin and stacked lamellar architectures of BCN nanosheets as shown in Figure 2a. This is also confirmed in Transmission Electron Microscopy (TEM) images (Figure 2b), in which a crumpled lamellar structure could be seen clearly. High-resolution TEM (HRTEM) (Inset of Figure 2b) discloses 3-5 parallel fringes on the folded edge of the nanosheets, suggesting 3-5 layers contained in the nanosheets. In addition, some wrinkled fringes on the nanosheets reveal a little disorder of the crystallization, 
corresponding to the XRD results. The interlayer distance is about $0.35 \mathrm{~nm}$, well in accordance with the interplane (002) spacing of $\mathrm{BCN}^{33}$ The Atomic Force Microscope (AFM) results (Figure 2c) further confirm the layered structure of BCN with a uniform thickness of $1.24 \mathrm{~nm}$, conforming to 3-4 stacked layers. Besides, a holey structure of BCN nanosheets could be well discerned in the AFM image (Figure S4), which could also be observed in the TEM image (Figure S2). The surface area and porosity of the materials are studied by Brunauer-EmmettTeller (BET) test. In Figure 2d, the nitrogen adsorption-desorption isotherms suggest a type IV curve with a visible H3 type hysteresis loop, demonstrating the presence of a size distribution of mesopores in the range of relative pressure $0.5-1.0 .^{22}$ The BET surface area and the total pore volume are calculated to be $817 \mathrm{~m}^{2} / \mathrm{g}$ and $0.624 \mathrm{~cm}^{3} / \mathrm{g}$ respectively, larger than previously reported gelatin derived $\mathrm{BCN}$ nanosheets $\left(416 \mathrm{~m}^{2} / \mathrm{g}\right) .{ }^{35}$ It is worth noting that soft templates P123 would lead to hydrogen bonding bridge in the polymer gel precursors, giving rise to more gaseous oxygen containing groups among chains in contrast with no P123 cured precursor (FigureS5). In the synthesis, some gases such as $\mathrm{CO}, \mathrm{CO}_{2}$ and $\mathrm{NH}_{3}$ are released through the spaces between layers during decomposition. Thus a larger number of pores are finally achieved. $^{48,49}$ The results implicate that such a porous structure of nanosheets with relative high BET surface could promote the ORR catalytic activities to a large extent. 
(a)

(e)
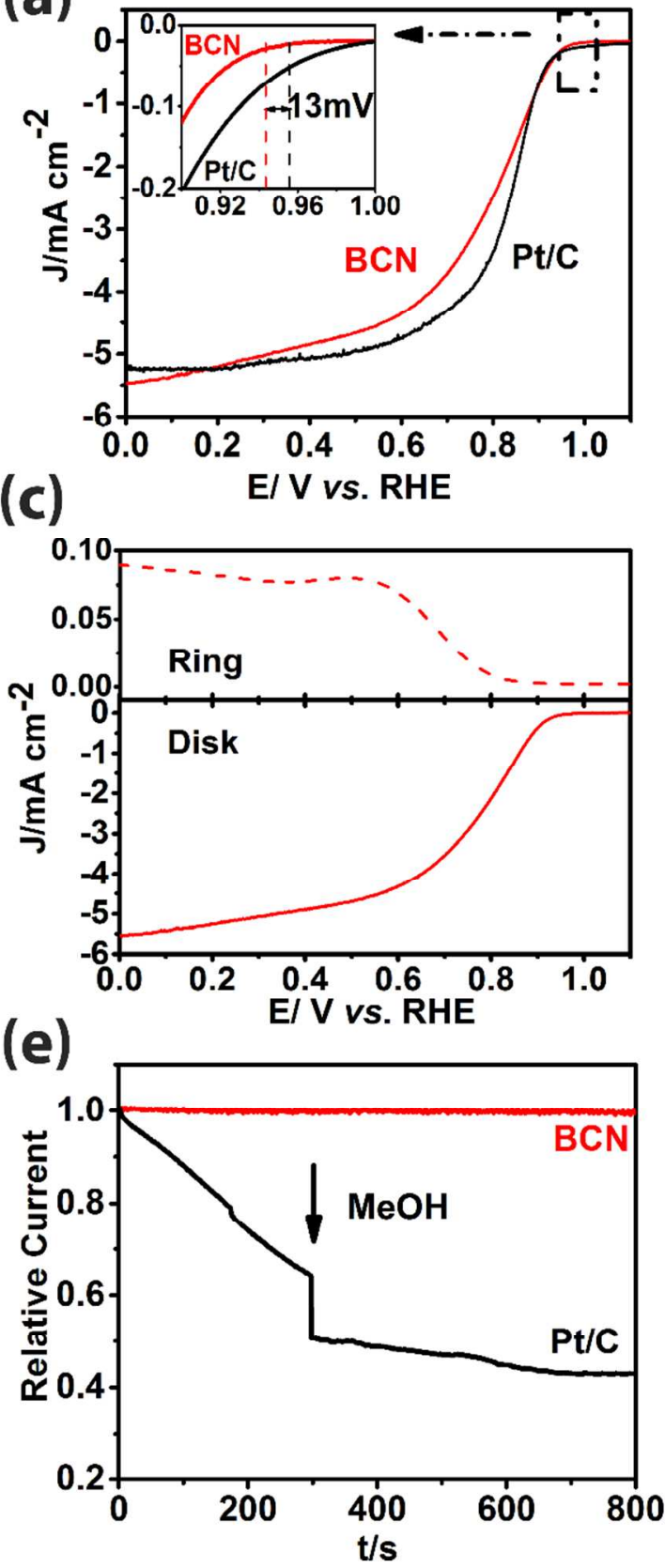

(b)

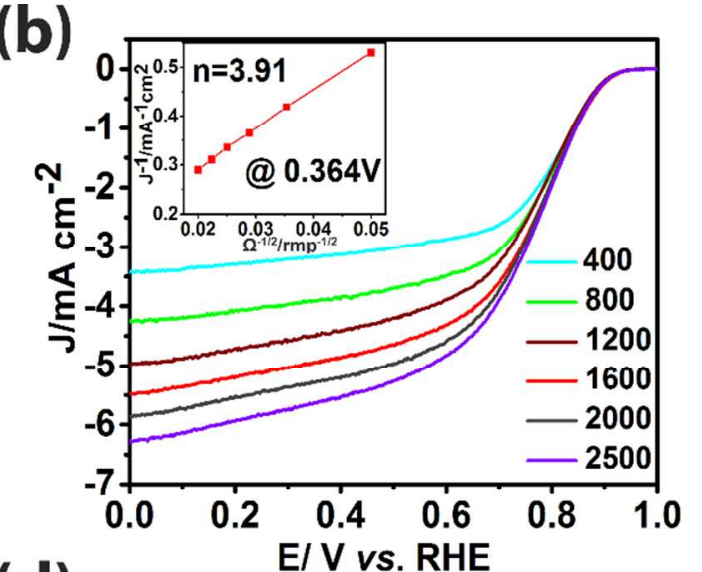

(d) E/ V vs. RHE

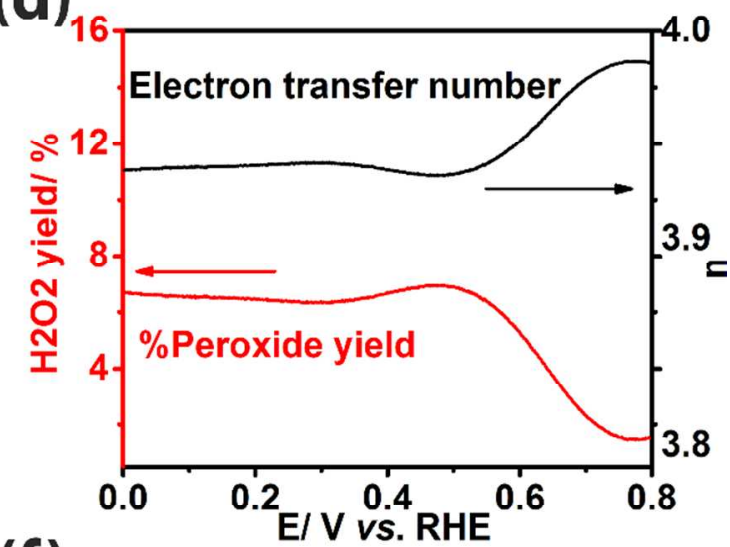

(f)

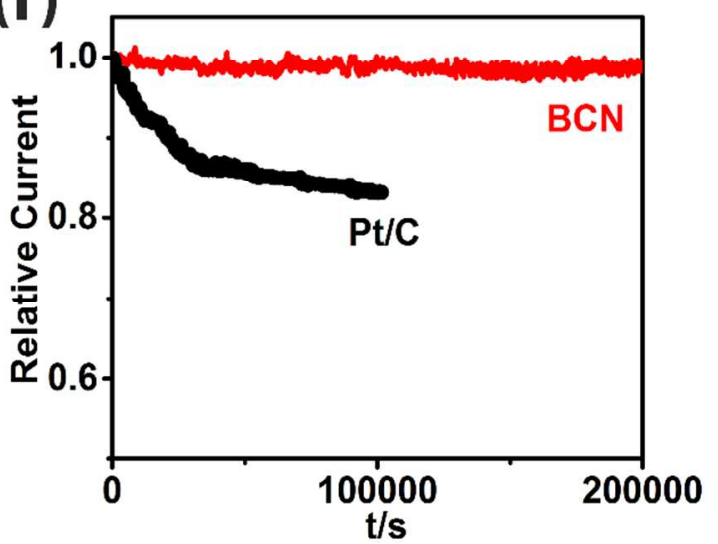

Figure 3. ORR catalytic performance of the porous few-layered $\mathrm{BCN}$ in $0.1 \mathrm{M} \mathrm{KOH}$. a) LSV curves of $\mathrm{BCN}$ catalysts and $\mathrm{Pt} / \mathrm{C}$ at a rotation rate of $1600 \mathrm{rpm}$ and a scan rate of $5 \mathrm{mV} / \mathrm{s}$. The inset shows the higher magnification of LSV curves between 0.9-1.0V vs. RHE. b) LSV curves of $\mathrm{BCN}$ catalysts with various rotation rates from $400 \mathrm{rpm}-2500 \mathrm{rpm}$ at a scan rate of $5 \mathrm{mV} / \mathrm{s}$. The inset shows the corresponding Koutecky-Levich plot. c) RRDE voltammograms and d) $\mathrm{H}_{2} \mathrm{O}_{2}$ yield corresponding to the total oxygen reduction products and the calculated electron transfer number of few-layered $\mathrm{BCN}$. e) Chronoamperometric measurement for few-layered $\mathrm{BCN}$ and $\mathrm{Pt} / \mathrm{C}$ in an $\mathrm{O}_{2}$-saturated $0.1 \mathrm{M} \mathrm{KOH}$ solution and when $3.0 \mathrm{M}$ methanol is added at around $300 \mathrm{~s}$ at an electrode rotation rate of $1600 \mathrm{rpm}$. f) Current-time chronoamperometric 
response of few-layered $\mathrm{BCN}$ and $\mathrm{Pt} / \mathrm{C}$ in an $\mathrm{O}_{2}$-saturated $0.1 \mathrm{M} \mathrm{KOH}$ solution at a rotation rate of $1600 \mathrm{rpm}$.

The ORR activity of the as-synthesized BCN nanosheets is investigated under alkaline condition (0.1M KOH) firstly. A Cyclic voltammetry (CV) (Figure S7a) reveals a well-defined and strong cathodic ORR peak at around $0.8 \mathrm{~V}$ vs. RHE, indicating the high catalytic activity of BCN nanosheets in alkaline environment. In addition, as shown in Figure 3a, the onset potential ( $\mathrm{E}_{\text {onset }}$ ) of the porous BCN nanosheets is $0.940 \mathrm{~V}$ vs. RHE, only $13 \mathrm{mV}$ less than $20 \% \mathrm{Pt} / \mathrm{C}$ (0.953V vs. RHE). And the half-wave potential $\left(\mathrm{E}_{1 / 2}\right)$ is $0.82 \mathrm{~V} v s$. RHE, which is dramatically close to that of Pt/C (0.84V vs. RHE) as well. ${ }^{12}$ Notably, the ORR activity of our sample is better than several other reported $\mathrm{B}, \mathrm{N}$ dual doped graphene or $\mathrm{BCN}$ nanomaterials with either $\mathrm{E}_{\text {onset, }}$ $\mathrm{E}_{1 / 2}$ or both potential being more positive (Table $\left.\mathrm{S} 1\right) .{ }^{36-45}$ The number (n) of electrons transferred per $\mathrm{O}_{2}$ molecule is estimated to be 3.91 at $0.364 \mathrm{~V}$ vs. RHE according to the Koutecky-Levich (K-L) plot built from the linear sweep voltammetry (LSV) curves under different electrode rotating speeds (Figure 3b), ${ }^{51,52}$ thus indicating a $4 \mathrm{e}^{-}$pathway for ORR. To further study the ORR performance in $0.1 \mathrm{M} \mathrm{KOH}$, the rotating ring-disk electrode (RRDE) measurement is conducted. Figure $3 \mathrm{c}$ displays both disk and ring currents for $\mathrm{BCN}$ nanosheets. The average electron number is measured to be 3.93 (Figure $3 \mathrm{~d}$ ), verifying the $4 \mathrm{e}^{-}$oxygen reduction selectivity again, well conforming to the results obtained from K-L plot. Furthermore, the calculated $\mathrm{H}_{2} \mathrm{O}_{2}$ yield is below $6 \%$, suggesting an efficient $4 \mathrm{e}^{-}$pathway ORR catalytic behavior. Moreover, the porous BCN nanosheets exhibit an outstanding tolerance for methanol cross-over effect (Figure 3f) and impressive long term durability (Figure 3d), which are both superior to commercial 20\% Pt/C. 
(a)

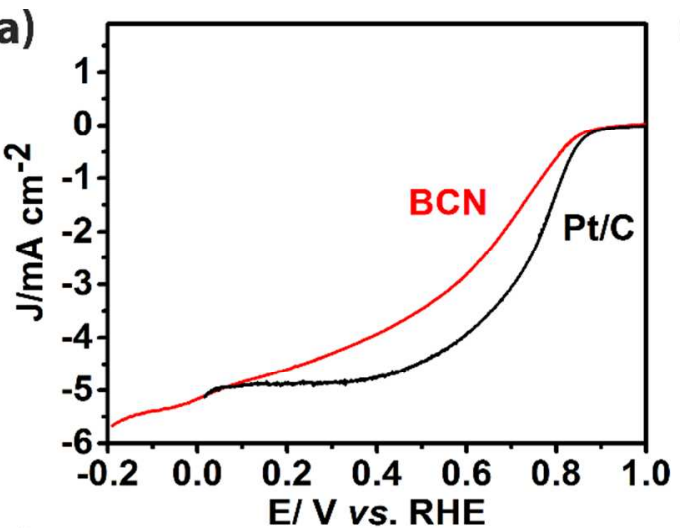

(c)

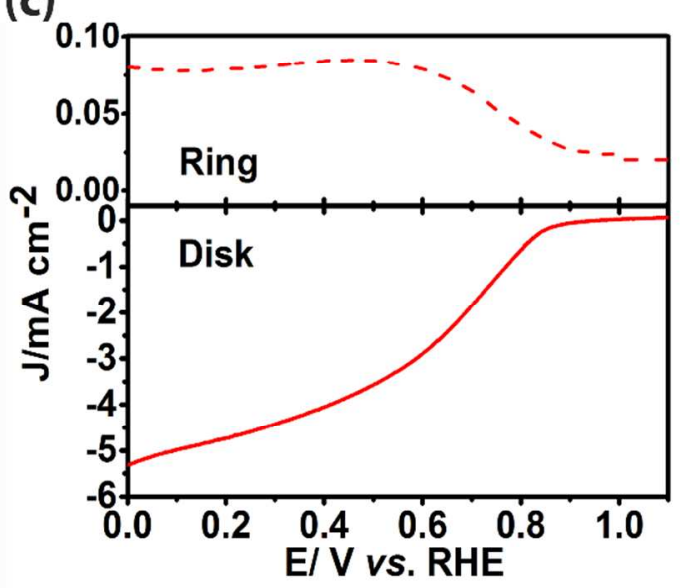

(e)

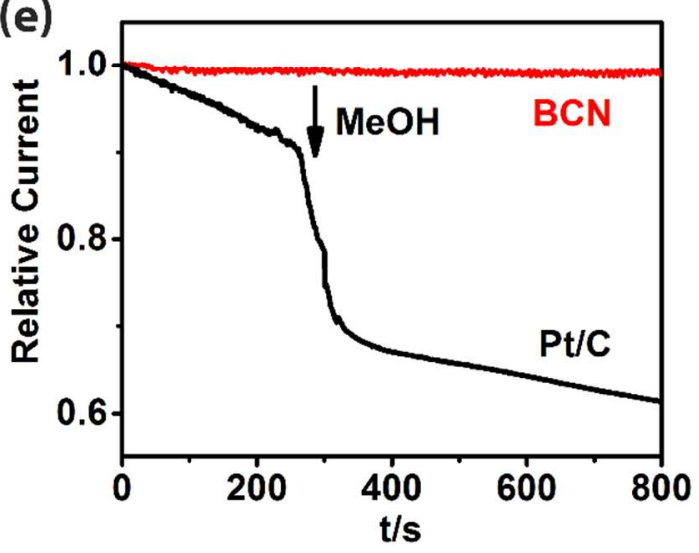

(b)

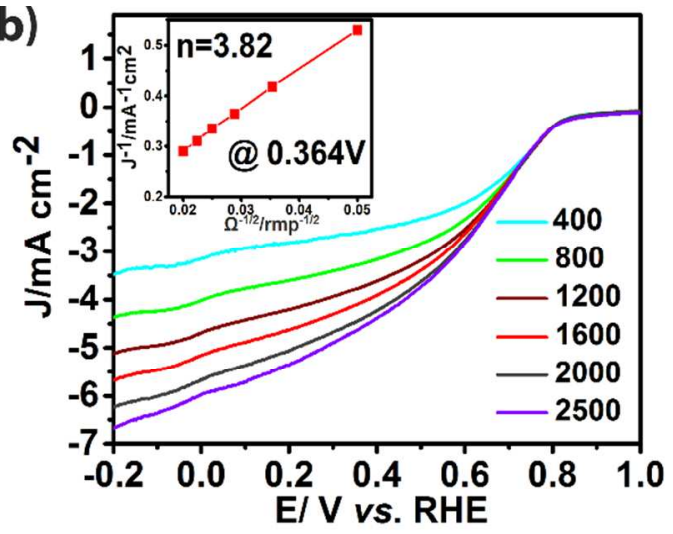

(d)

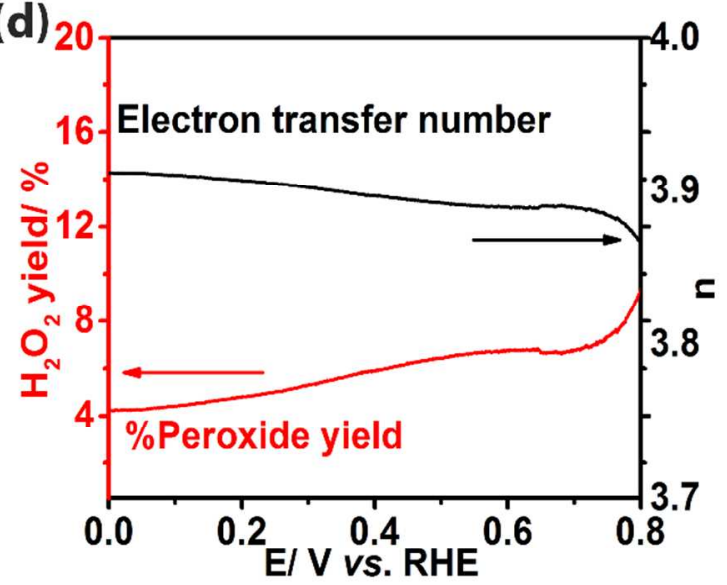

(f)

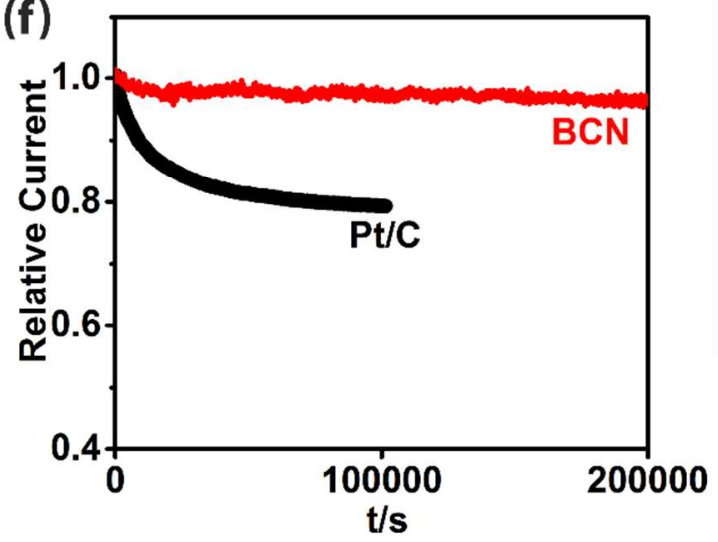

Figure 4. ORR catalytic performance of the porous few-layered $\mathrm{BCN}$ in $0.1 \mathrm{M} \mathrm{HClO}_{4}$. a) $\mathrm{LSV}$ curves of $\mathrm{BCN}$ catalysts and $\mathrm{Pt} / \mathrm{C}$ at a rotation rate of $1600 \mathrm{rpm}$ and a scan rate of $5 \mathrm{mV} / \mathrm{s} . \mathrm{b}$ ) LSV curves of BCN catalysts with various rotation rates from $400 \mathrm{rpm}-2500 \mathrm{rpm}$ at a scan rate of $5 \mathrm{mV} / \mathrm{s}$. The inset shows the corresponding Koutecky-Levich plot. c) RRDE voltammograms and d) $\mathrm{H}_{2} \mathrm{O}_{2}$ yield corresponding to the total oxygen reduction products and the calculated electron transfer number of few-layered BCN. e) Chronoamperometric measurement for fewlayered $\mathrm{BCN}$ and $\mathrm{Pt} / \mathrm{C}$ in an $\mathrm{O}_{2}$-saturated $0.1 \mathrm{M} \mathrm{HClO}_{4}$ solution and when $3.0 \mathrm{M}$ methanol is added at around $300 \mathrm{~s}$ at an electrode rotation rate of $1600 \mathrm{rpm}$. f) Current-time chronoamperometric response of few-layered $\mathrm{BCN}$ and $\mathrm{Pt} / \mathrm{C}$ in an $\mathrm{O}_{2}$-saturated $0.1 \mathrm{M} \mathrm{HClO}_{4}$ solution at a rotation rate of $1600 \mathrm{rpm}$. 
It is of great importance that the as-obtained BCN catalysts also exhibit excellent ORR activity and stability in acidic $0.1 \mathrm{M} \mathrm{HClO}_{4}$. A distinct cathodic peak could be clearly observed in Figure S7b. Although the onset potential $\left(\mathrm{E}_{\text {onset }}\right)$ of our BCN catalyst $(0.84 \mathrm{~V} v s$. RHE) is slightly less than $\mathrm{Pt} / \mathrm{C}(0.93 \mathrm{~V} v s . \mathrm{RHE})$ in Figure 4a, it is fully comparable and even better than the most recently reported state-of-the-art carbon materials including heteroatoms doped CNT/graphene or Fe/N doped CNTs in acid environment (See Table S2). ${ }^{12-17}$ Besides, the K-L plot in Figure $4 \mathrm{~b}$ inset ( $\mathrm{n}=3.82$ at $0.364 \mathrm{~V}$ vs. RHE) and RRDE measurement results in Figure $4 \mathrm{c}$ and d (average $\mathrm{n}=3.88$ ) both confirm a $4 \mathrm{e}^{-}$transfer route for $\mathrm{BCN}$ nanosheets in $0.1 \mathrm{M} \mathrm{HClO}_{4}$. Furthermore, the peroxide yield is lower than $8 \%$ at all potentials, disclosing the high $\mathrm{O}_{2}$ reduction selectivity even in acid condition. More significantly, the nearly unchanged durability and tolerance for $\mathrm{MeOH}$ cross-over effect (Figure $4 \mathrm{e}$ and $4 \mathrm{f}$ ) demonstrate the feasibility of the porous BCN nanosheets as potential candidates in PEM fuel cells again.

In respect to the chemical compositional, structural and morphological characterizations of the porous BCN nanosheets, the superior ORR catalytic activity and stability could be ascribed to several aspects. Firstly, high concentration of pyridinic N (38.64\%) doped into the nanosheets could accelerate $\mathrm{O}_{2}$ adsorption by reducing the local work function and providing more Lewis base sites next to carbon, which are energetically favoured as adsorption sites by oxygen molecules. ${ }^{50,56}$ Therefore, the number of the activated carbon atoms are boomed with the nitrogen doping. ${ }^{57,58}$ Secondly, recent studies reveal that B-N-C edge groups play a crucial role to enhance the ORR performance. ${ }^{27,40}$ Notably, although isolated BN domains are inactive as the ORR catalysts, ${ }^{37,39}$ the edge B-N-C groups may boost the ORR catalytic activity. In our sample, it is likely that abundant B-N-C (27.6 at.\%) bonding is easily accessible to $\mathrm{OH}$ adsorption and $\mathrm{O}$ protonation in the graphitic carbon edge area. ${ }^{53,55}$ As a consequence, the ORR activity is further 
presumably improved at B-N-C edge. Thirdly, heteropolar B-N bonding as well as ionized B-O bonds provides an extra dipole, thereby likely enhancing the relative wettability (hydrophilicity) between electrolyte and electrode materials and develops a faster $\mathrm{O}_{2}$ transfer kinetic mechanism. ${ }^{29-31}$ Furthermore, the large surface area facilitates more active sites. The micropores and mesopores in our sample are able to support a shorter ion-transport pathway, preferably realizing the exchange of molecules and ions in the electrolytes. ${ }^{30}$ In addition, although the ORR catalytic performance in acid environment is inferior to that of alkaline, the difference is relatively minor in contrast with some of other carbon materials. ${ }^{12-16}$ For single nitrogen-doped carbon materials in low $\mathrm{pH}$ solutions, the increased proton concentration degrades the ORR reaction kinetics with the protonation of negatively charged $\mathrm{N}$ atoms. ${ }^{59}$ However, for $\mathrm{BCN}$ nanosheets, the positively charged B atoms might alleviate the effect of protonation process, thereby narrowing the gap of ORR catalytic activity between alkaline and acid environment. Briefly, the stimulative $\mathrm{B}, \mathrm{N}$ dual-doping effects discussed above and the $2 \mathrm{D}$ nanostructure with hierarchical porosity make our BCN nanosheets a remarkable low-cost and highly efficient ORR metal-free catalysts in both alkaline and acid media.

In summary, we have designed a novel, simple, and scalable polymer sol-gel approach to directly synthesize porous and few-layered $\mathrm{BCN}$ nanosheets. The B, N co-doping, 2Dnanostructure and high surface area with rational porosity enable the $\mathrm{BCN}$ nanosheets to be efficient as ORR catalysts. In the alkaline medium, the sample displays comparable activity, greater methanol durability and better stability than $20 \% \mathrm{Pt} / \mathrm{C}$. More importantly, the as-obtained catalysts also demonstrate considerable ORR performance in strong acid environment, superior to some other carbon materials. Therefore, this study provides an effective method to construct 
new BCN nanomaterials as high-efficiency metal-free ORR electrocatalysts in both alkaline and acid conditions, which could satisfy the greater desire of commercial PEMFCs.

\section{ASSOCIATED CONTENT}

\section{Supporting Information.}

Experimental details, Figures of XPS Survey Spectra of the porous BCN nanosheets, TEM, SEM and AFM images of the porous BCN nanosheets, Nitrogen adsorption/desorption isotherms and TEM images of BCN nanosheets synthesized without adding P123, CV curves of BCN nanosheets for ORR in $\mathrm{N}_{2}$ and $\mathrm{O}_{2}$ saturated solution in $0.1 \mathrm{M} \mathrm{KOH}$ solution and $0.1 \mathrm{M} \mathrm{HClO}_{4}$ solution. RDE linear sweep voltammograms (LSV) curves of graphite+BN (mole ratios=6.7:1), pure graphite and $\mathrm{BCN}$ at a rotation rate of $1600 \mathrm{rpm}$ and a scan rate of $5 \mathrm{mV} / \mathrm{s}$ in $0.1 \mathrm{M} \mathrm{KOH}$ solution. Table of comparison of several reported B,N-doped graphene and borocarbonitride nanosheets as ORR catalysts in alkaline conditions, Table of comparison of latest reported carbon materials (metal free and Fe containing) with high ORR performances in acid solutions.

\section{AUTHOR INFORMATION \\ Email: weiwei.lei@deakin.edu.au}

\section{ACKNOWLEDGMENT}

This work was financially supported by the Australian Research Council Discovery Program, the Australian Research Council Discovery Early Career Researcher Award scheme (DE150101617 and DE140100716), and Deakin University, Central Research Grant Scheme. We thank Prof. Qipeng Guo for discussing the synthesis of materials. 


\section{REFERENCES}

(1) Xia,W.; Liang, Z.; Zou, R.; Guo, S. Earth-abundant nanomaterials for oxygen reduction. Angew. Chem., Int. Ed. 2015, 54, 2-29.

(2) Wang, D.; Xin, H. L.; Hovden, R.; Wang, H.; Yu, Y.; Muller, D. A.; DiSalvo, F. J.; Abruna, H. D. Structurally ordered intermetallic platinum-cobalt core-shell nanoparticles with enhanced activity and stability as oxygen reduction electrocatalysts. Nature mater. 2013, 12, 8187.

(3) Nie, Y.; Li, L.; Wei, Z. Recent advancements in Pt and Pt-free catalysts for oxygen reduction reaction. Chem. Soc. Rev. 2015, 44, 2168-2201.

(4) Zhou, M.; Wang, H. L.; Guo, S. Towards high-efficiency nanoelectrocatalysts for oxygen reduction through engineering advanced carbon nanomaterials. Chem. Soc. Rev. 2016, 45, 12731307.

(5) Geng, D.; Ding, N.; Andy Hor, T. S.; Liu, Z.; Sun, X.; Zong, Y. Potential of metal-free "graphene alloy" as electrocatalysts for oxygen reduction reaction. J. Mater. Chem. A 2015, 3, 1795-1810.

(6) Chia, X.; Eng, A. Y. S.; Ambrosi, A.; Tan, S. M.; Pumera, M. Electrochemistry of nanostructured layered transition-metal dichalcogenides. Chem. Rev. 2015, 115, 11941-11966.

(7) Sa, Y. J.; Park, C.; Jeong, H. Y.; Park, S. H.; Lee, Z.; Kim, K. T.; Park, G. G.; Joo, S. H. Carbon nanotubes/heteroatom-doped carbon core-sheath nanostructures as highly active, metalfree oxygen reduction electrocatalysts for alkaline fuel cells. Angew. Chem., Int. Ed. 2014, 53, 4102-4106. 
(8) Ye, T.; Lv, L.; Li, X.; Xu, M.; Chen, J. Strongly veined carbon nanoleaves as a highly efficient metal-free electrocatalyst. Angew. Chem., Int. Ed. 2014, 53, 6905-6909.

(9) Zhao, Z.; Li, M.; Zhang, L.; Dai, L.; Xia, Z. Design principles for heteroatom-doped carbon nanomaterials as highly efficient catalysts for fuel cells and metal-air batteries. Adv. mater. 2015, 27, 6834-6840.

(10) Wang, X.; Sun, G.; Routh, P.; Kim, D. H.; Huang, W.; Chen, P. Heteroatom-doped graphene materials: syntheses, properties and applications. Chem. Soc. Rev. 2014, 43, 70677098.

(11) Jiao, Y.; Zheng, Y.; Jaroniec, M.; Qiao, S. Z. Origin of the electrocatalytic oxygen reduction activity of graphene-based catalysts: a roadmap to achieve the best performance. $J$. Am. Chem. Soc. 2014, 136, 4394-4403.

(12) Shui,J. M. W., Du, F.; Dai, L. N-doped carbon nanomaterials are durable catalysts for oxygen reduction reaction in acidic fuel cells. $S c i$. $A d v$. 2015, 10, 444-448.

(13) Zhang, J.; Zhao, Z.; Xia, Z.; Dai, L. A metal-free bifunctional electrocatalyst for oxygen reduction and oxygen evolution reactions. Nature Nanotech. 2015, 10, 444-452.

(14) Yang, J.; Sun, H.; Liang, H.; Ji, H.; Song, L.; Gao, C.; Xu, H. A highly efficient metalfree oxygen reduction electrocatalyst assembled from carbon nanotubes and graphene. $A d v$. mater. 2016, 28, 4606-4613.

(15) Wei, W.; Liang, H.; Parvez, K.; Zhuang, X.; Feng, X.; Mullen, K. Nitrogen-doped carbon nanosheets with size-defined mesopores as highly efficient metal-free catalyst for the oxygen reduction reaction. Angew. Chem., Int. Ed. 2014, 53, 1596-1600. 
(16) Li, Y.; Zhou, W.; Wang, H.; Xie, L.; Liang, Y.; Wei, F.; Idrobo, J. C.; Pennycook, S. J.; Dai, H. An oxygen reduction electrocatalyst based on carbon nanotube-graphene complexes. Nature Nanotech. 2012, 7, 394-400.

(17) Lv, H.; Li, D.; Strmcnik, D.; Paulikas, A. P.; Markovic, N. M.; Stamenkovic, V. R. Recent advances in the design of tailored nanomaterials for efficient oxygen reduction reaction. Nano Energy 2016, DOI:10.1016/j.nanoen.2016.04.008.

(18) Chabot, V.; Higgins, D.; Yu, A.; Xiao, X.; Chen, Z.; Zhang, J. A review of graphene and graphene oxide sponge: material synthesis and applications to energy and the environment. Energy Environ. Sci. 2014, 7, 1564-1596.

(19) Zhou, X.; Qiao, J.; Yang, L.; Zhang, J. A review of graphene-based nanostructural materials for both catalyst supports and metal-free catalysts in PEM fuel cell oxygen reduction reactions. Adv. Energy Mater. 2014, 4, 1301523, DOI: 10.1002/aenm.201301523.

(20) Liu, D.; He, L.; Lei, W.; Klika, K. D.; Kong, L.; Chen, Y. Multifunctional polymer/porous boron nitride nanosheet membranes for superior trapping emulsified oils and organic molecules. Adv. Mater. Interfaces 2015, 2, 1500228.

(21) Lei, W.; Zhang, H.; Wu, Y.; Zhang, B.; Liu, D.; Qin, S.; Liu, Z.; Liu, L.; Ma, Y.; Chen, Y. Oxygen-doped boron nitride nanosheets with excellent performance in hydrogen storage. Nano Energy 2014, 6, 219-224.

(22) Lei, W.; Portehault, D.; Liu, D.; Qin, S.; Chen, Y. Porous boron nitride nanosheets for effective water cleaning. Nat. Commun. 2013, 4, 1777-1784. 
(23) Liu, D.; Lei, W.; Qin, S.; Klika, K. D.; Chen, Y. Superior adsorption of pharmaceutical molecules by highly porous BN nanosheets. Phys. Chem. Chem. Phys. 2016, 18, 84-88.

(24) Lei, W.; Liu, D.; Chen, Y. Highly crumpled boron nitride nanosheets as adsorbents: scalable solvent-less production. Adv. Mater. Interfaces 2015, 2, 1400529.

(25) Liu, D.; Lei, W.; Qin, S.; Chen, Y. Template-free synthesis of functional 3D BN architecture for removal of dyes from water. Sci. rep. 2014, 4, 4453.

(26) Lei,W.; Portehault, D.; Dimova, R.; Antonietti, M. Boron carbon nitride nanostructures from salt melts: tunable water-soluble phosphors. J. Am. Chem. Soc. 2011, 133, 7121-7127.

(27) Wu, J.; Rodrigues, M. F.; Vajtai, R.; Ajayan, P. M. Tuning the electrochemical reactivity of boron- and nitrogen-substituted graphene. Adv. mater. 2016, 28, 6239-6246.

(28) Kumar, N.; Moses, K.; Pramoda, K.; Shirodkar, S. N.; Mishra, A. K.; Waghmare, U. V.; Sundaresan, A.; Rao, C. N. Borocarbonitrides, BxCyNz. J. Mater. Chem. A 2013, 1, 5806-5813.

(29) Wu, Z.; Ren, W.; Xu, L.; Li, F.; Cheng, H. Doped graphene sheets as anode materials with super high rate and large capacity for lithium ion batteries. ACS Nano 2011, 5, 5463-5471.

(30) Guo, H.; Gao, Q. Boron and nitrogen co-doped porous carbon and its enhanced properties as supercapacitor. J. Power Sources 2009, 186, 551-556.

(31) Konno, H.; Ito, T.; Ushiro, M.; Fushimi, K.; Azumi, K. High capacitance B/C/N composites for capacitor electrodes synthesized by a simple method. J. Power Sources 2010, 195, 1739-1746. 
(32) Lei, W.; Qin, S.; Liu, D.; Portehault, D.; Liu, Z.; Chen, Y. Large scale boron carbon nitride nanosheets with enhanced lithium storage capabilities. Chem. commun. 2013, 49, 352354.

(33) Moses, K.; Kiran, V.; Sampath, S.; Rao, C. N. Few-layer borocarbonitride nanosheets: platinum-free catalyst for the oxygen reduction reaction. Chem. Asian J. 2014, 9, 838-843.

(34) Chhetri, M.; Maitra, S.; Chakraborty, H.; Waghmare, U. V.; Rao, C. N. Superior performance of borocarbonitrides, $\mathrm{BxCyNz}$, as stable, low-cost metal-free electrocatalysts for the hydrogen evolution reaction. Energy Environ. Sci. 2016, 9, 95-101.

(35) Ling, Z.; Wang, Z.; Zhang, M.; Yu, C.; Wang, G.; Dong, Y.; Liu, S.; Wang, Y.; Qiu, J. Sustainable synthesis and assembly of biomass-derived B/N co-doped carbon nanosheets with ultrahigh aspect ratio for high-performance supercapacitors. Adv. Funct. Mater. 2016, 26, 111119.

(36) Wang, S.; Iyyamperumal, E.; Roy, A.; Xue, Y.; Yu, D.; Dai, L. Vertically aligned BCN nanotubes as efficient metal-free electrocatalysts for the oxygen reduction reaction: a synergetic effect by co-doping with boron and nitrogen. Angew. Chem., Int. Ed. 2011, 50, 11756-11760.

(37) Zhao, Y.; Yang, L.; Chen, S.; Wang, X.; Ma, Y.; Wu, Q.; Jiang, Y.; Qian, W.; Hu, Z. Can boron and nitrogen co-doping improve oxygen reduction reaction activity of carbon nanotubes? J. Am. Chem. Soc. 2013, 135, 1201-1204.

(38) Wang, S.; Zhang, L.; Xia, Z.; Roy, A.; Chang, D. W.; Baek, J. B.; Dai, L. BCN graphene as efficient metal-free electrocatalyst for the oxygen reduction reaction. Angew. Chem., Int. Ed. 2012, 51, 4209-4212. 
(39) Zheng, Y.; Jiao, Y.; Ge, L.; Jaroniec, M.; Qiao, S. Z. Two-step boron and nitrogen doping in graphene for enhanced synergistic catalysis. Angew. Chem., Int. Ed. 2013, 52, 3110-3116.

(40) Gong, Y.; Fei, H.; Zou, X.; Zhou, W.; Yang, S.; Ye, G.; Liu, Z.; Peng, Z.; Lou, J.; Vajtai, R. et al. Boron- and nitrogen-substituted graphene nanoribbons as efficient catalysts for oxygen reduction reaction. Chem. Mater. 2015, 27, 1181-1186.

(41) Xue, Y.; Yu, D.; Dai, L.; Wang, R.; Li, D.; Roy, A.; Lu, F.; Chen, H.; Liu, Y.; Qu, J. Three-dimensional B,N-doped graphene foam as a metal-free catalyst for oxygen reduction reaction. Phys. Chem. Chem. Phys. 2013, 15, 12220-12226.

(42) Wang, Z.; Cao, X.; Ping, J.; Wang, Y.; Lin, T.; Huang, X.; Ma, Q.; Wang, F.; He, C.; Zhang, H. Electrochemical doping of three-dimensional graphene networks used as efficient electrocatalysts for oxygen reduction reaction. Nanoscale 2015, 7, 9394-9398.

(43) Shi, Q.; Lei, Y.; Wang, Y.; Wang, H.; Jiang, L.; Yuan, H.; Fang, D.; Wang, B.; Wu, N.; Gou, Y. B, N-codoped 3D micro-/mesoporous carbon nanofibers web as efficient metal-free catalysts for oxygen reduction. Curr. Appl. Phys. 2015, 15, 1606-1614.

(44) Jiang, Z.; Zhao, X.; Tian, X.; Luo, L.; Fang, J.; Gao, H.; Jiang, Z. J. Hydrothermal synthesis of boron and nitrogen codoped hollow graphene microspheres with enhanced electrocatalytic activity for oxygen reduction reaction. ACS Appl. Mater. Interfaces 2015, 7 , 19398-19407.

(45) Wang, L.; Yu, P.; Zhao, L.; Tian, C.; Zhao, D.; Zhou, W.; Yin, J.; Wang, R.; Fu, H. B and $\mathrm{N}$ isolate-doped graphitic carbon nanosheets from nitrogen-containing ion-exchanged resins for enhanced oxygen reduction. Sci. Rep. 2014, 4, 5184. 
(46) Ci, L.; Song, L.; Jin, C.; Jariwala, D.; Wu, D.; Li, Y.; Srivastava, A.; Wang, Z. F.; Storr, K.; Balicas, L.; Liu et al. Atomic layers of hybridized boron nitride and graphene domains. Nature Mater. 2010, 9, 430-435.

(47) Qin, L.; Yu, J.; Kuang, S.; Xiao, C.; Bai, X. Few-atomic-layered boron carbonitride nanosheets prepared by chemical vapor deposition. Nanoscale 2012, 4, 120-123.

(48) Li, J.; Xiao, X.; Xu, X.; Lin, J.; Huang, Y.; Xue, Y.; Jin, P.; Zou, J.; Tang, C. Activated boron nitride as an effective adsorbent for metal ions and organic pollutants. Sci. Rep. 2013, 3, 3208.

(49) Bayatsarmadi, B.; Zheng, Y.; Jaroniec, M.; Qiao, S. Z. Soft-templating synthesis of Ndoped mesoporous carbon nanospheres for enhanced oxygen reduction reaction. Chem. Asian J. 2015, 10, 1546-1553.

(50) Yang, W.; Liu, X.; Yue, X.; Jia, J.; Guo, S. Bamboo-like carbon nanotube/Fe3C nanoparticle hybrids and their highly efficient catalysis for oxygen reduction. J. Am. Chem. Soc. 2015, 137, 1436-1439.

(51) Liu, X.; Antonietti, M. Moderating black powder chemistry for the synthesis of doped and highly porous graphene nanoplatelets and their use in electrocatalysis. Adv. mater. 2013, 25, 6284-90.

(52) Liu, D.; Lei, W.; Portehault, D.; Qin, S.; Chen, Y. High N-content holey few-layered graphene electrocatalysts: scalable solvent-less production. J. Mater. Chem. A 2015, 3, 16821687. 
(53) Liu, X.; Wang, Y.; Dong, L.; Chen, X.; Xin, G.; Zhang, Y.; Zang, J. One-step synthesis of shell/core structural boron and nitrogen co-doped graphitic carbon/nanodiamond as efficient electrocatalyst for the oxygen reduction reaction in alkaline media. Electrochim. Acta 2016, 194, $161-167$.

(54) Dou, S.; Huang, X.; Ma, Z.; Wu, J.; Wang, S. A simple approach to the synthesis of BCN graphene with high capacitance. Nanotechnology 2015, 26, 045402.

(55) Lai, L.; Potts, J. R.; Zhan, D.; Wang, L.; Poh, C. K.; Tang, C.; Gong, H.; Shen, Z.; Lin, J.; Ruoff, R. S. Exploration of the active center structure of nitrogen-doped graphene-based catalysts for oxygen reduction reaction. Energy Environ. Sci. 2012, 5, 7936-7942.

(56) Guo, D.; Shibuya, R.; Akiba,C.; Saji, S.;Kondo, T.; Nakamura, J. ORR Active sites of nitrogen-doped carbon materials for oxygen reduction reaction clarified using model catalysts. Science 2016, 351, 6271-6275.

(57) Wan, K.; Long, G.; Liu, M.; Du, L.; Liang, Z.; Tsiakaras, P. Nitrogen-doped ordered mesoporous carbon: synthesis and active sites for electrocatalysis of oxygen reduction reaction. Appl. Catal., B. 2015, 165, 566-571.

(58) Long, G.; Wan, K.; Liu, M.; Li, X.; Liang, Z.; Piao, J. Effect of pyrolysis conditions on nitrogen-doped ordered mesoporous carbon electrocatalysts. Chin. J. Catal. 2015, 36, 1197-1204.

(59) Wan, K.; Yu, Z.; Li, X.; Liu, M.; Yang, G.; Piao, J.; Liang, Z. pH effect on electrochemistry of nitrogen-doped carbon catalyst for oxygen reduction reaction. ACS Catal. 2015, 5, 4325-4332. 


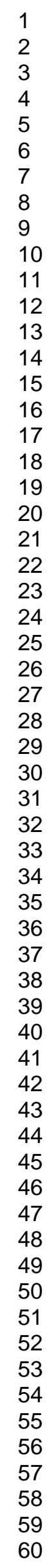

ACS Paragon Plus Environment 